ORIGINAL ARTICLE

\section{Everolimus-Eluting Stents or Bypass Surgery for Multivessel Coronary Disease}

\author{
Sripal Bangalore, M.D., M.H.A., Yu Guo, M.A., Zaza Samadashvili, M.D., \\ Saul Blecker, M.D., Jinfeng Xu, Ph.D., and Edward L. Hannan, Ph.D.
}

\section{BACKGROUND}

Results of trials and registry studies have shown lower long-term mortality after coronary-artery bypass grafting (CABG) than after percutaneous coronary intervention (PCI) among patients with multivessel disease. These previous analyses did not evaluate PCI with second-generation drug-eluting stents.

\section{METHODS}

In an observational registry study, we compared the outcomes in patients with multivessel disease who underwent CABG with the outcomes in those who underwent PCI with the use of everolimus-eluting stents. The primary outcome was allcause mortality. Secondary outcomes were the rates of myocardial infarction, stroke, and repeat revascularization. Propensity-score matching was used to assemble a cohort of patients with similar baseline characteristics.

\section{RESULTS}

Among 34,819 eligible patients, 9223 patients who underwent PCI with everolimuseluting stents and 9223 who underwent CABG had similar propensity scores and were included in the analyses. At a mean follow-up of 2.9 years, PCI with everolimuseluting stents, as compared with CABG, was associated with a similar risk of death (3.1\% per year and 2.9\% per year, respectively; hazard ratio, 1.04; $95 \%$ confidence interval [CI], 0.93 to 1.17; $\mathrm{P}=0.50)$, higher risks of myocardial infarction ( $1.9 \%$ per year vs. $1.1 \%$ per year; hazard ratio, $1.51 ; 95 \% \mathrm{CI}, 1.29$ to 1.77 ; $\mathrm{P}<0.001$ ) and repeat revascularization (7.2\% per year vs. 3.1\% per year; hazard ratio, 2.35 ; 95\% CI, 2.14 to 2.58 ; $\mathrm{P}<0.001)$, and a lower risk of stroke $(0.7 \%$ per year vs. $1.0 \%$ per year; hazard ratio, $0.62 ; 95 \% \mathrm{CI}, 0.50$ to 0.76 ; $\mathrm{P}<0.001$ ). The higher risk of myocardial infarction with PCI than with CABG was not significant among patients with complete revascularization but was significant among those with incomplete revascularization ( $\mathrm{P}=0.02$ for interaction).

\section{CONCLUSIONS}

In a contemporary clinical-practice registry study, the risk of death associated with PCI with everolimus-eluting stents was similar to that associated with CABG. PCI was associated with a higher risk of myocardial infarction (among patients with incomplete revascularization) and repeat revascularization but a lower risk of stroke. (Funded by Abbott Vascular.)
From New York University School of Medicine, New York (S. Bangalore, Y.G., S. Blecker, J.X.); and the School of Public Health, State University of New York at Albany, Albany (Z.S., E.L.H.). Address reprint requests to Dr. Bangalore at the Cardiovascular Clinical Research Center, New York University School of Medicine, New York, NY 10016, or at sripalbangalore@ gmail.com.

This article was published on March 16, 2015, at NEJM.org.

N EnglJ Med 2015;372:1213-22. DOI: 10.1056/NEJMoal412168 Copyright (๑) 2015 Massachusetts Medical Society. 
ORONARY-ARTERY BYPASS GRAFTING (CABG) and percutaneous coronary intervention (PCI) are treatment options for patients with multivessel coronary artery disease. Prior studies have shown a mortality benefit of CABG, as compared with PCI. ${ }^{1-4}$ However, these studies compared CABG with balloon angioplasty, bare-metal stents, or first-generation drugeluting stents. Second-generation drug-eluting stents have thinner struts and have thinner and more biocompatible polymer with more uniform polymer coating of the strut surface, resulting in less inflammation and thrombogenicity, as compared with the first-generation drug-eluting stents and even bare-metal stents. ${ }^{5}$

Consequently, the newer-generation drugeluting stents, especially the everolimus-eluting stent, have been shown to reduce the risks of death, myocardial infarction, and stent thrombosis, as compared with bare-metal stents or first-generation drug-eluting stents. ${ }^{6,7}$ However, previous studies did not compare CABG with PCI with the use of second-generation drugeluting stents. The recommendations of various national and international guidelines are based on studies of CABG versus PCI with the use of older-generation stents, but these guidelines have been applied routinely to contemporary practice. ${ }^{8}$

Our objective was to evaluate the outcomes with CABG, as compared with PCI with the use of everolimus-eluting stents, in patients who had multivessel coronary artery disease. We used a contemporary clinical-practice registry to identify participants.

\section{METHODS}

\section{STUDY DESIGN AND OVERSIGHT}

This study was a registry-based analysis involving patients with multivessel coronary artery disease who underwent isolated CABG surgery and patients who underwent PCI with everolimuseluting stents between January 1, 2008, and December 31, 2011, in New York. The study was designed by the first and last authors and was funded by Abbott Vascular. The registry data were collected by the data coordinators at participating hospitals. The second and fifth authors performed the analysis. The first author prepared the first draft of the manuscript, which was then reviewed and edited by the coauthors. The sponsor, who had no role in the design or conduct of the study, had the right to suggest changes to the manuscript, but final decisions regarding the content were made solely by the authors. The first and last authors accept full responsibility for the accuracy and completeness of the reported analyses and interpretations of the data.

\section{REGISTRIES}

The patients included in the study were identified from the Cardiac Surgery Reporting System (CSRS) and Percutaneous Coronary Intervention Reporting System (PCIRS) registries of the New York State Department of Health. No informed consent was required, because the data are anonymized. To obtain follow-up information, the CSRS and PCIRS were linked with the New York State Vital Statistics Death registry with the use of patient identifiers and to the Statewide Planning and Research Cooperative System registry with the use of patient identifiers, unique hospital identifiers, and dates of admission, surgery, and discharge. Details regarding the registries are included in the Supplementary Appendix, available with the full text of this article at NEJM.org.

\section{STUDY POPULATION}

Patients were eligible for inclusion in the study if they had multivessel disease, which was defined as severe stenosis ( $\geq 70 \%$ ) in at least two diseased major epicardial coronary arteries, and if they had undergone either PCI with implantation of an everolimus-eluting stent or CABG. Exclusion criteria were the following: revascularization within 1 year before the index procedure; previous cardiac surgery (CABG or valve surgery), because such patients are less likely to undergo repeat CABG than to undergo PCI; severe left main coronary artery disease (degree of stenosis, $\geq 50 \%$ ); PCI with a stent other than an everolimus-eluting stent or with a combination of stents; myocardial infarction within 24 hours before the index procedure; and unstable hemodynamics or cardiogenic shock.

\section{OUTCOMES}

The primary outcome of the study was all-cause mortality. Various secondary outcomes were also assessed, including the rates of myocardial infarc- 
tion, stroke, and repeat revascularization. Myocardial infarction was defined as either procedural, if it occurred as a complication after PCI or CABG (defined in both the CSRS and PCIRS registries as the presence of new $\mathrm{Q}$ waves), or spontaneous, if it was diagnosed at readmission (i.e., as an emergency admission with a principal diagnosis of myocardial infarction or a principal diagnosis of cardiogenic shock with a secondary diagnosis of myocardial infarction).

Stroke was categorized as occurring either within 30 days (in which case it was presumed to be a complication of the index procedure) or after 30 days (on the basis of readmission with a principal diagnosis of stroke). Repeat revascularization was identified as any unstaged revascularization after the index procedure; staged revascularization was defined as non-targetvessel revascularization within 90 days after the index procedure. In addition, short-term events (those occurring in the hospital or $\leq 30$ days after the procedure) were tabulated separately.

\section{STATISTICAL ANALYSIS}

Given the differences in the baseline characteristics between eligible participants in the two groups (Table 1), propensity-score matching was used to identify a cohort of patients with similar baseline characteristics. The propensity score is a conditional probability of having a particular exposure (PCI with everolimus-eluting stents versus $\mathrm{CABG}$ ) given a set of baseline measured covariates. ${ }^{9,10}$ The propensity score was estimated with the use of a nonparsimonious multivariable logistic-regression model, ${ }^{11}$ with PCI with the use of everolimus-eluting stents as the dependent variable and all the baseline characteristics outlined in Table 1 as covariates. Matching was performed with the use of a 1:1 matching protocol without replacement (greedy-matching algorithm), with a caliper width equal to 0.2 of the standard deviation of the logit of the propensity score. Standardized differences were estimated for all the baseline covariates before and after matching to assess prematch imbalance and postmatch balance. ${ }^{12}$ Standardized differences of less than $10.0 \%$ for a given covariate indicate a relatively small imbalance. ${ }^{12}$

In the matched cohort, paired comparisons were performed with the use of McNemar's test for binary variables and a paired Student's t-test or paired-sample test for continuous variables. The comparative risks of primary and secondary outcomes were further adjusted for in the matched cohort with the use of a Cox proportional-hazards regression model that was stratified on the matched pair to preserve the benefit of matching.

Prespecified subgroup analyses were performed on the basis of two types of characteristics. Anatomical subgroups were based on threevessel disease versus two-vessel disease, with or without involvement of the territory of the proximal left anterior descending coronary artery, and on complete revascularization versus incomplete revascularization in the PCI cohort. Clinical subgroups were based on age $(<80$ years vs. $\geq 80$ years), diabetes status (yes or no), and left ventricular ejection fraction $(\geq 40 \%$ vs. $<40 \%$ ). In the subgroup analyses, to maintain the baseline balance between the PCI group and the CABG group, only the corresponding matched pairs in a subgroup were chosen. For example, in the subgroup of patients with diabetes, only the matched pairs of patients with diabetes in the PCI group and in the CABG group were included in the analysis. Tests for interaction were performed to assess for heterogeneity of treatment effect among subgroups.

Analyses of the primary and secondary outcomes were also performed in a separate propensity-matched cohort of patients who underwent CABG versus those who underwent PCI with first-generation drug-eluting stents (sirolimus-eluting or paclitaxel-eluting stents) and in a propensity-matched cohort of patients who underwent PCI with everolimus-eluting stents versus those who underwent PCI with first-generation drug-eluting stents.

All reported $\mathrm{P}$ values are two-sided and have not been adjusted for multiple testing. All the analyses were performed with the use of SAS software, version 9.3 (SAS Institute).

\section{RESULTS}

\section{STUDY POPULATION}

We identified 34,819 patients with multivessel disease who met our inclusion criteria (Fig. 1), of whom 16,876 (48.5\%) underwent PCI with evero- 


\begin{tabular}{|c|c|c|c|c|c|c|}
\hline \multirow[t]{3}{*}{ Characteristic } & \multicolumn{3}{|c|}{ Before Matching } & \multicolumn{3}{|c|}{ After Matching } \\
\hline & $\begin{array}{c}\mathrm{PCl} \\
(\mathrm{N}=16,876)\end{array}$ & $\begin{array}{c}\text { CABG } \\
(\mathrm{N}=17,943)\end{array}$ & $\begin{array}{c}\text { Standardized } \\
\text { Difference }\end{array}$ & $\begin{array}{c}\mathrm{PCl} \\
(\mathrm{N}=9223)\end{array}$ & $\begin{array}{c}\text { CABG } \\
(N=9223)\end{array}$ & $\begin{array}{c}\text { Standardized } \\
\text { Difference }\end{array}$ \\
\hline & & & $\%$ & & & $\%$ \\
\hline \multicolumn{7}{|l|}{ Age } \\
\hline Mean (yr) & $65.0 \pm 11.2$ & $65.3 \pm 10.6$ & 2.4 & $65.1 \pm 11.1$ & $65.1 \pm 10.8$ & 0.5 \\
\hline \multicolumn{7}{|l|}{ Distribution (\%) } \\
\hline$<59 \mathrm{yr}$ & 32.2 & 29.4 & 6.0 & 31.2 & 30.7 & 0.9 \\
\hline $60-69 \mathrm{yr}$ & 31.8 & 33.9 & 4.4 & 32.8 & 33.1 & 0.6 \\
\hline $70-79 \mathrm{yr}$ & 25.6 & 27.5 & 4.5 & 26.4 & 26.0 & 0.8 \\
\hline$\geq 80 \mathrm{yr}$ & 10.4 & 9.1 & 4.4 & 9.6 & 10.1 & 1.6 \\
\hline \multicolumn{7}{|l|}{$\operatorname{Sex}(\%)$} \\
\hline Male & 70.8 & 74.2 & 7.7 & 72.6 & 72.9 & 0.7 \\
\hline Female & 29.2 & 25.8 & 7.7 & 27.4 & 27.1 & 0.7 \\
\hline Body-surface area $\left(\mathrm{m}^{2}\right)$ & $2.03 \pm 0.27$ & $2.04 \pm 0.27$ & $<0.1$ & $2.04 \pm 0.27$ & $2.04 \pm 0.27$ & 0.2 \\
\hline Hispanic ethnic group (\%) $\dagger$ & 12.4 & 8.9 & 11.4 & 11.0 & 11.0 & 0.0 \\
\hline \multicolumn{7}{|l|}{ Race (\%)† } \\
\hline White & 76.7 & 85.1 & 21.6 & 81.0 & 81.5 & 1.2 \\
\hline Black & 11.2 & 7.7 & 12.1 & 9.3 & 9.1 & 0.7 \\
\hline Other & 12.1 & 7.2 & 16.8 & 9.7 & 9.4 & 0.9 \\
\hline Diabetes (\%) & 39.0 & 40.6 & 3.1 & 39.0 & 39.5 & 1.2 \\
\hline \multicolumn{7}{|l|}{ Ejection fraction (\%) } \\
\hline$<20 \%$ & 0.6 & 1.5 & 9.7 & 0.8 & 0.8 & 0.5 \\
\hline $20-29 \%$ & 2.9 & 6.5 & 16.8 & 4.1 & 4.4 & 1.4 \\
\hline $30-39 \%$ & 5.0 & 11.4 & 23.8 & 7.2 & 7.4 & 0.6 \\
\hline $40-49 \%$ & 12.2 & 19.0 & 18.7 & 15.7 & 15.4 & 1.0 \\
\hline$\geq 50 \%$ & 74.5 & 61.3 & 28.5 & 71.7 & 71.6 & 0.4 \\
\hline Data missing & 4.8 & 0.3 & 29.1 & 0.5 & 0.5 & 0.5 \\
\hline \multicolumn{7}{|l|}{ Previous myocardial infarction (\%) } \\
\hline 1-7 Days before treatment & 15.2 & 18.5 & 8.6 & 17.0 & 16.8 & 0.4 \\
\hline 8-14 Days before treatment & 1.2 & 5.2 & 23.0 & 2.0 & 2.0 & 0.5 \\
\hline 15-20 Days before treatment & 0.3 & 1.0 & 8.9 & 0.4 & 0.5 & 1.6 \\
\hline$>20$ Days before treatment & 17.5 & 22.4 & 12.1 & 19.5 & 19.5 & 0.1 \\
\hline None & 65.8 & 53.0 & 26.3 & 61.2 & 61.1 & 0.1 \\
\hline Cerebrovascular disease (\%) & 2.4 & 7.6 & 24.1 & 3.6 & 3.8 & 1.0 \\
\hline Peripheral arterial disease (\%) & 8.6 & 11.6 & 9.9 & 9.6 & 9.8 & 0.5 \\
\hline COPD (\%) & 5.3 & 12.5 & 25.4 & 7.6 & 7.7 & 0.4 \\
\hline \multicolumn{7}{|l|}{ Congestive heart failure (\%) } \\
\hline None & 93.9 & 85.2 & 28.8 & 91.3 & 91.2 & 0.4 \\
\hline At current admission & 3.7 & 11.7 & 30.4 & 5.8 & 6.0 & 0.8 \\
\hline Before current admission & 2.4 & 3.1 & 4.4 & 2.8 & 2.7 & 0.5 \\
\hline
\end{tabular}




\begin{tabular}{|c|c|c|c|c|c|c|}
\hline \multicolumn{7}{|l|}{ Table 1. (Continued.) } \\
\hline \multirow[t]{3}{*}{ Characteristic } & \multicolumn{3}{|c|}{ Before Matching } & \multicolumn{3}{|c|}{ After Matching } \\
\hline & $\begin{array}{c}\mathrm{PCl} \\
(\mathrm{N}=16,876)\end{array}$ & $\begin{array}{c}\text { CABG } \\
(\mathrm{N}=17,943)\end{array}$ & $\begin{array}{l}\text { Standardized } \\
\text { Difference }\end{array}$ & $\begin{array}{c}\mathrm{PCl} \\
(\mathrm{N}=9223)\end{array}$ & $\begin{array}{c}\text { CABG } \\
(N=9223)\end{array}$ & $\begin{array}{c}\text { Standardized } \\
\text { Difference }\end{array}$ \\
\hline & & & $\%$ & & & $\%$ \\
\hline Malignant ventricular arrhythmia (\%) & 0.4 & 0.8 & 6.3 & 0.5 & 0.6 & 0.9 \\
\hline \multicolumn{7}{|l|}{ Renal failure (\%) } \\
\hline Requiring dialysis & 2.5 & 2.8 & 2.3 & 2.4 & 2.7 & 1.5 \\
\hline \multicolumn{7}{|l|}{$\begin{array}{l}\text { Creatinine level in patients not } \\
\text { requiring dialysist }\end{array}$} \\
\hline$<1.3 \mathrm{mg} / \mathrm{dl}$ & 78.2 & 73.6 & 10.9 & 77.1 & 76.4 & 1.8 \\
\hline $1.3-1.5 \mathrm{mg} / \mathrm{dl}$ & 12.2 & 13.4 & 3.8 & 12.6 & 13.0 & 1.1 \\
\hline $1.6-2.0 \mathrm{mg} / \mathrm{dl}$ & 5.0 & 6.7 & 6.9 & 5.4 & 5.5 & 0.3 \\
\hline$>2.0 \mathrm{mg} / \mathrm{dl}$ & 2.1 & 3.5 & 8.4 & 2.4 & 2.5 & 0.5 \\
\hline \multicolumn{7}{|l|}{ No. of diseased vessels (\%) } \\
\hline \multicolumn{7}{|l|}{2} \\
\hline With proximal LAD artery & 18.8 & 17.8 & 2.7 & 26.3 & 25.9 & 0.8 \\
\hline Without proximal LAD artery & 55.1 & 15.7 & 90.5 & 29.5 & 29.2 & 0.5 \\
\hline \multicolumn{7}{|l|}{3} \\
\hline With proximal LAD artery & 8.6 & 35.5 & 68.7 & 15.3 & 15.2 & 0.4 \\
\hline Without proximal LAD artery & 17.5 & 31.0 & 32.0 & 28.9 & 29.6 & 1.6 \\
\hline Prior PCl (\%) & 31.7 & 18.0 & 32.0 & 24.5 & 24.1 & 1.0 \\
\hline \multicolumn{7}{|c|}{$\begin{array}{l}\text { Plus-minus values are means } \pm S D \text {. The standardized differences are reported as percentages; a difference of less than } 10.0 \% \text { indicates a } \\
\text { relatively small imbalance. CABG denotes coronary-artery bypass grafting, COPD chronic obstructive pulmonary disease, LAD left anterior } \\
\text { descending, and PCI percutaneous coronary intervention. } \\
\dagger \text { Race and ethnic group were self-reported. } \\
\text { To convert the values for creatinine to micromoles per liter, multiply by } 88.4 \text {. }\end{array}$} \\
\hline
\end{tabular}

limus-eluting stents and 17,943 (51.5\%) underwent CABG (Table 1). Before propensity-score matching, there were differences between the two groups in several of the baseline variables (Table 1). With the use of propensity-score matching, 9223 patients who underwent PCI with the use of everolimus-eluting stents were matched with 9223 patients who underwent CABG. The C-statistic for the model was 0.814 . After matching, the standardized differences were less than $10.0 \%$ for all variables, indicating only small differences between the two groups (Table 1).

\section{SHORT-TERM OUTCOMES}

Short-term outcomes (in the hospital or $\leq 30$ days after the index procedure) favored PCI with everolimus-eluting stents over CABG. PCI was associated with significantly lower risks of death ( $0.6 \%$ vs. $1.1 \%$; hazard ratio, $0.49 ; 95 \%$ confidence interval [CI], 0.35 to $0.69 ; \mathrm{P}<0.001)$ and stroke $(0.2 \%$ vs. $1.2 \%$; hazard ratio, $0.18 ; 95 \% \mathrm{CI}$, 0.11 to 0.29 ; $\mathrm{P}<0.001$ ), but there was no significant difference between the two groups in the risk of myocardial infarction $(0.5 \%$ and $0.4 \%$, respectively; hazard ratio, $1.37 ; 95 \% \mathrm{CI}, 0.89$ to 2.12; $\mathrm{P}=0.16)$.

\section{PRIMARY OUTCOME}

After a mean follow-up of 2.9 years, PCI with everolimus-eluting stents was associated with a risk of death that was similar to that associated with CABG $(3.1 \%$ and $2.9 \%$ per year, respectively; hazard ratio, $1.04 ; 95 \% \mathrm{CI}, 0.93$ to $1.17 ; \mathrm{P}=0.50$ ) 


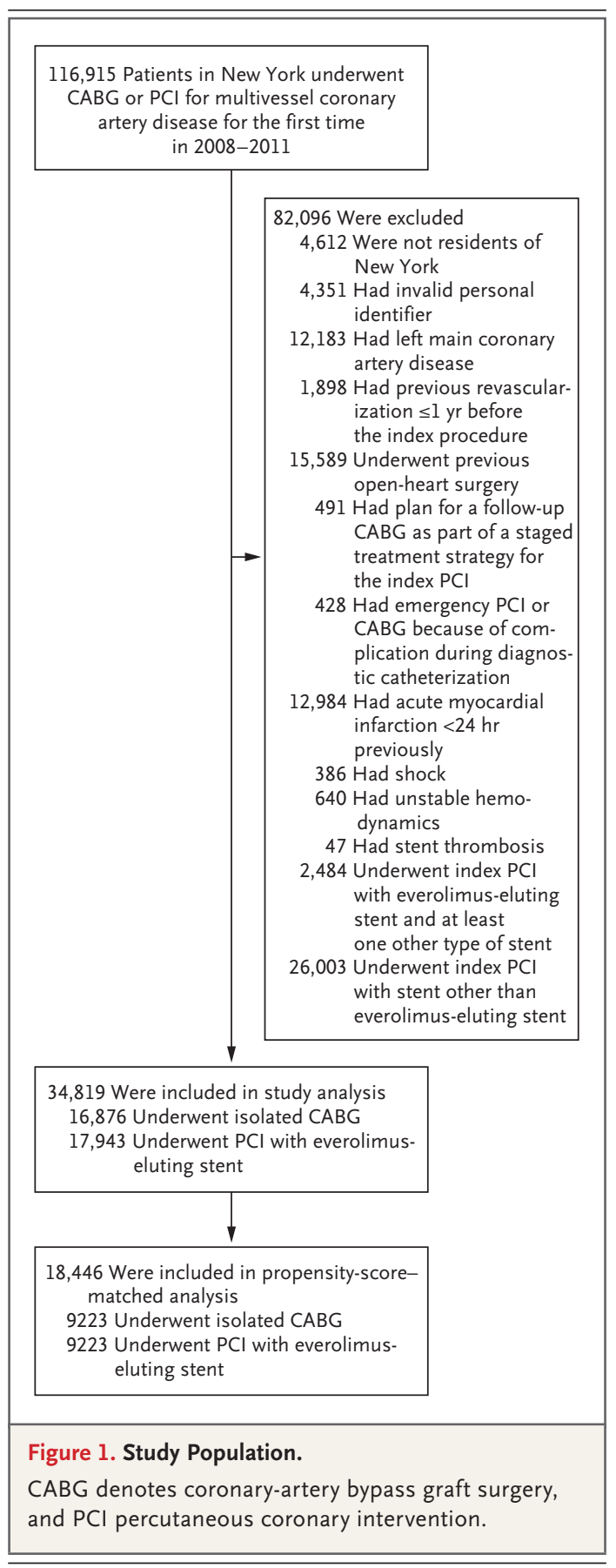

(Table 2 and Fig. 2A). The results were largely similar in the subgroup analyses that were based on vessel anatomy (Table S1 in the Supplementary Appendix) and clinical characteristics (Table S2 in the Supplementary Appendix), including in the subgroup analysis that was based on diabetes status ( $\mathrm{P}=0.45$ for interaction).

\section{MYOCARDIAL INFARCTION}

PCI with everolimus-eluting stents was associated with a higher risk of a first myocardial infarction than was CABG $(1.9 \%$ vs. $1.1 \%$ per year; hazard ratio, 1.51; $95 \% \mathrm{CI}, 1.29$ to 1.77 ; $\mathrm{P}<0.001$ ) (Table 2 and Fig. 2B). This higher risk of myocardial infarction after PCI was driven by a higher risk of spontaneous myocardial infarction (hazard ratio, 1.55; 95\% CI, 1.31 to 1.82; $\mathrm{P}<0.001$ ), with no significant difference between the two study groups in the risk of procedural myocardial infarction (hazard ratio, 1.36; 95\% CI, 0.68 to $2.71 ; \mathrm{P}=0.39$ ). The higher risk of myocardial infarction after PCI with everolimus-eluting stents, as compared with CABG, was not significant in matched pairs in which the patient in the PCI group had complete revascularization but was significant in pairs in which the patient in the PCI group had incomplete revascularization ( $\mathrm{P}=0.02$ for interaction) (Table S1 in the Supplementary Appendix). The results were generally similar in other subgroups (Tables S1 and S2 in the Supplementary Appendix) with a higher risk of myocardial infarction with PCI than with CABG, although there was a nonsignificant trend toward a less pronounced difference among patients with two-vessel disease than among those with three-vessel disease ( $\mathrm{P}=0.14$ for interaction) (Table S1 in the Supplementary Appendix).

\section{STROKE}

PCI with everolimus-eluting stents was associated with a lower risk of a first stroke than was CABG $(0.7 \%$ vs. $1.0 \%$ per year; hazard ratio, 0.62 ; $95 \%$ CI, 0.50 to 0.76 ; $\mathrm{P}<0.001$ ) (Table 2 and Fig. $2 \mathrm{C})$. The difference was driven largely by a lower short-term ( $\leq 30$ days) risk of stroke with PCI with everolimus-eluting stents, as compared with CABG (hazard ratio, 0.18 ; $95 \%$ CI, 0.11 to 0.29 ; $\mathrm{P}<0.001$ ), with no significant difference in a landmark analysis that examined only events after 30 days (hazard ratio, 1.05; 95\% CI, 0.81 to 1.37; $\mathrm{P}=0.69$ ). The results were generally similar in subgroup analyses (Tables S1 and S2 in the Supplementary Appendix).

\section{REPEAT REVASCULARIZATION}

PCI with everolimus-eluting stents was associated with a higher risk of a first repeat-revascularization procedure than was CABG $(7.2 \%$ vs. $3.1 \%$ per year; hazard ratio, 2.35; 95\% CI, 2.14 to 2.58 ; $\mathrm{P}<0.001$ ) (Table 2 and Fig. 2D). This difference 
was less pronounced among patients with twovessel disease than among those with three-vessel disease ( $\mathrm{P}=0.02$ for interaction), although CABG was favored in both (Table S1 in the Supplementary Appendix). Similarly, the difference between PCI and CABG was less pronounced in the subgroup of patients who had complete revascularization than it was in the subgroup of those who had incomplete revascularization ( $\mathrm{P}<0.001$ for interaction), again with CABG favored in both (Table S1 in the Supplementary Appendix). The results were largely similar (in favor of CABG) in the other subgroups (Tables S1 and S2 in the Supplementary Appendix). Among all repeat revascularizations in the two study groups, most repeat revascularizations were performed by means of PCI $(92.6 \%)$, with only a minority being performed by means of CABG (7.4\%).

\section{SENSITIVITY ANALYSIS}

In an analysis of CABG versus PCI with first-generation drug-eluting stents (6128 matched pairs), CABG was associated with nonsignificantly lower rates of death $(2.7 \%$ and $3.0 \%$ per year, respectively; $\mathrm{P}=0.21$ ) and with significantly lower risks of myocardial infarction $(\mathrm{P}<0.001)$ and revascularization $(\mathrm{P}<0.001)$ but with a trend toward a higher risk of stroke $(\mathrm{P}=0.05)$ (Table $\mathrm{S} 3$ in the Supplementary Appendix). In an analysis of PCI with everolimus-eluting stents versus PCI with first-generation drug-eluting stents (8801 matched pairs), everolimus-eluting stents were associated with lower risks of myocardial infarction $(\mathrm{P}<0.001)$ and revascularization $(\mathrm{P}=0.03)$ but similar risks of other outcomes (Table S4 in the Supplementary Appendix).

\section{DISCUSSION}

In a contemporary cohort of patients with multivessel coronary artery disease, the risk of death associated with PCI with everolimus-eluting stents was similar to that associated with CABG. PCI was associated with a higher risk of myocardial infarction (mainly among patients who had incomplete revascularization) and repeat revascularization, whereas CABG was associated with an increased risk of stroke. Short-term results favored PCI, with lower risks of death and stroke.

Randomized trials comparing PCI with CABG have not been typically powered to evaluate differences in the rates of myocardial infarction,

\begin{tabular}{|c|c|c|c|c|}
\hline \multirow[t]{2}{*}{ Outcome } & \multirow[t]{2}{*}{$\begin{array}{l}\text { No. of Patients } \\
\text { with Event }\end{array}$} & $\begin{array}{l}\text { Event } \\
\text { Rate }\end{array}$ & \multirow[t]{2}{*}{$\begin{array}{c}\text { Hazard Ratio } \\
(95 \% \mathrm{CI})\end{array}$} & \multirow[t]{2}{*}{$P$ Value } \\
\hline & & $\% / \gamma r$ & & \\
\hline \multicolumn{5}{|l|}{ Death } \\
\hline $\mathrm{PCl}$ & 768 & 3.10 & $1.04(0.93-1.17)$ & 0.50 \\
\hline CABG & 815 & 2.86 & Reference & \\
\hline \multicolumn{5}{|c|}{ Myocardial infarction } \\
\hline $\mathrm{PCl}$ & 462 & 1.87 & $1.51(1.29-1.77)$ & $<0.001$ \\
\hline CABG & 322 & 1.13 & Reference & \\
\hline \multicolumn{5}{|l|}{ Stroke } \\
\hline $\mathrm{PCl}$ & 178 & 0.72 & $0.62(0.50-0.76)$ & $<0.001$ \\
\hline CABG & 277 & 0.97 & Reference & \\
\hline \multicolumn{5}{|c|}{ Revascularization } \\
\hline $\mathrm{PCl}$ & 1793 & 7.25 & $2.35(2.14-2.58)$ & $<0.001$ \\
\hline CABG & 883 & 3.10 & Reference & \\
\hline
\end{tabular}

* The propensity-score-matched cohort included 9223 patients in the $\mathrm{PCI}$ group and 9223 patients in the CABG group.

stroke, and death from any cause; instead, they have been based on composite outcomes that include repeat revascularization. To create data sets of sufficient size to analyze these less frequent outcomes, one option is to perform metaanalyses of clinical-trial data. For example, one recent meta-analysis included six trials (involving 6055 patients) comparing PCI with the use of either first-generation drug-eluting stents or bare-metal stents with CABG. ${ }^{13}$ Rates of death, myocardial infarction, and repeat revascularization were significantly lower with CABG than with PCI, with a trend toward a higher rate of stroke with CABG.

Another approach is to use clinical-practice registries or other observational data sets. For example, in one analysis that included nearly 190,000 patients from the American College of Cardiology Foundation PCI Registry and the Society of Thoracic Surgeons Adult Cardiac Surgery Database, in which adjustment was made for propensity scores and inverse probability weighting, mortality at 4 years was lower among patients who had undergone CABG than among those who had undergone PCI $(78 \%$ of whom had received first-generation drug-eluting stents). ${ }^{14}$ 


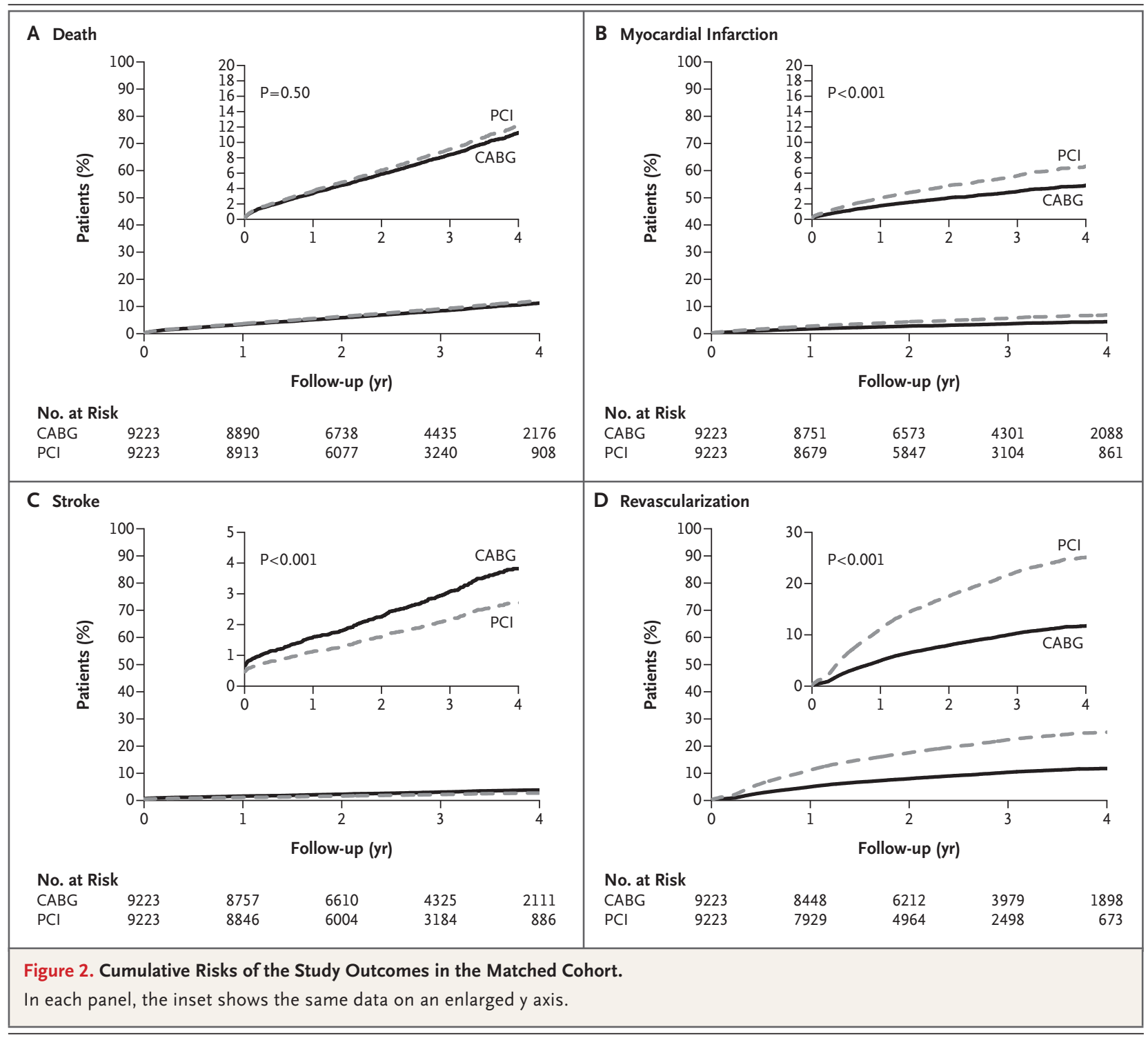

The relevance of these previous studies to current-day PCI with second-generation drugeluting stents is debatable. Restenosis and stent thrombosis are two potentially serious complications of PCI, which are associated with significant increases in the rates of myocardial infarction and death. ${ }^{15,16} \mathrm{~A}$ wealth of data from studies of second-generation drug-eluting stents, especially everolimus-eluting stents, have shown reductions in the risks of death, myocardial infarction, and stent thrombosis when such stents are compared with bare-metal stents or firstgeneration drug-eluting stents. . $^{6,7,17,18}$ Data from the New York State registries show a gradual bridging of the gap between CABG and PCI with respect to mortality, from the balloon-angioplasty era (40 to $50 \%$ reduction in mortality with CABG among patients with three-vessel disease), ${ }^{2}$ to the bare-metal-stent era (24 to 36\% reduction), ${ }^{3}$ to the era of first-generation drug-eluting stents (20 to $29 \%$ reduction), ${ }^{4}$ to the use of secondgeneration drug-eluting stents (no significant reduction in the present study). Data from the New York State registries also show decreases in the rate of repeat revascularization with PCI, from the balloon-angioplasty era $(37.0 \%$ of patients), ${ }^{2}$ to the bare-metal-stent era $(35.1 \%),{ }^{3}$ to the era of first-generation drug-eluting stents $(30.6 \%),{ }^{4}$ to the use of second-generation drugeluting stents (19.4\% in the present study). 
In the current study, PCI with the use of everolimus-eluting stents was associated with a higher risk of myocardial infarction than CABG. However, this difference in risk was not significant in the subgroup of matched pairs in which the patients who underwent PCI had complete revascularization. Incomplete revascularization has been shown to be associated with a significant increase in the risks of death and myocardial infarction. ${ }^{19,20}$ Thus, the choice between CABG and PCI with everolimus-eluting stents may depend on whether complete revascularization can be achieved with PCI. If the answer is yes, the choice between PCI and CABG should be made on the basis of weighing the short-term risk of death and stroke with CABG against the longterm risk of repeat revascularization with PCI. If complete revascularization does not appear to be feasible on the basis of anatomy, our data then suggest that such patients do better with CABG.

Some limitations of our analysis should be considered. This was a nonrandomized, observational study and hence suffers from potential selection and ascertainment bias despite robust propensity-score matching. The registries did not capture variables such as hypertension, hyperlipidemia, and smoking status, factors that affect long-term outcomes; therefore these variables could not be included in the propensity scores. The database does not distinguish between the cobalt-chromium and platinum-chromium everolimus-eluting stents. In addition, analyses stratified according to Synergy between PCI with Taxus and Cardiac Surgery (SYNTAX; www.syntaxscore .com) score could not be performed, owing to insufficient data to calculate the score. We did not have data on stent thrombosis. However, most stent thrombosis results in death or myocardial infarction, which are outcomes that were captured in the present study. In addition, the study did not include other neurologic outcomes, such as cognitive decline or transient ischemic attacks. The definition of procedural myocardial infarction did not capture events determined by biomarker elevations, because the routine collection of biomarkers after the procedure is not mandated in New York.

In conclusion, in this contemporary cohort of patients with multivessel coronary artery disease, PCI with everolimus-eluting stents, as compared with CABG, was associated with lower shortterm risks of death and stroke and with a similar long-term risk of death. PCI was also associated with a higher risk of myocardial infarction (among patients who had incomplete revascularization) and repeat revascularization, whereas CABG was associated with a higher risk of stroke.

Supported by Abbott Vascular.

Disclosure forms provided by the authors are available with the full text of this article at NEJM.org.
REFERENCES

1. Mohr FW, Morice MC, Kappetein AP, et al. Coronary artery bypass graft surgery versus percutaneous coronary intervention in patients with three-vessel disease and left main coronary disease: 5-year follow-up of the randomised, clinical SYNTAX trial. Lancet 2013;381:62938.

2. Hannan EL, Racz MJ, McCallister BD et al. A comparison of three-year survival after coronary artery bypass graft surgery and percutaneous transluminal coronary angioplasty. J Am Coll Cardiol 1999;33:6372.

3. Hannan EL, Racz MJ, Walford G, et al. Long-term outcomes of coronary-artery bypass grafting versus stent implantation. N Engl J Med 2005;352:2174-83.

4. Hannan EL, Wu C, Walford G, et al. Drug-eluting stents vs. coronary-artery bypass grafting in multivessel coronary disease. N Engl J Med 2008;358:331-41.

5. Kolandaivelu K, Swaminathan R, Gibson WJ, et al. Stent thrombogenicity early in high-risk interventional settings is driven by stent design and deployment and protected by polymer-drug coatings. Circulation 2011;123:1400-9.

6. Bangalore S, Toklu B, Amoroso N, et al. Bare metal stents, durable polymer drug eluting stents, and biodegradable polymer drug eluting stents for coronary artery disease: mixed treatment comparison meta-analysis. BMJ 2013;347:f6625.

7. Sarno G, Lagerqvist B, Fröbert $O$, et al. Lower risk of stent thrombosis and restenosis with unrestricted use of 'newgeneration' drug-eluting stents: a report from the nationwide Swedish Coronary Angiography and Angioplasty Registry (SCAAR). Eur Heart J 2012;33:606-13.

8. 2014 ESC/EACTS guidelines on myocardial revascularization: the Task Force on Myocardial Revascularization of the European Society of Cardiology (ESC) and the European Association for Cardio-Thoracic Surgery (EACTS) developed with the special contribution of the European Association of Percutaneous Cardiovascular Interventions (EAPCI). Eur Heart J 2014; 35:2541-619.

9. Rosenbaum P, Rubin D. The central role of propensity score in observational studies for causal effects. Biometrika 1983; 70:41-55.

10. Rubin D. Using propensity score to help design observational studies: application to the tobacco litigation. Health Serv Outcomes Res Methodol 2001;2:169-88.

11. Ahmed A, Husain A, Love TE, et al. Heart failure, chronic diuretic use, and increase in mortality and hospitalization: an observational study using propensity score methods. Eur Heart J 2006;27:1431-9. 12. Normand ST, Landrum MB, Guadagnoli E, et al. Validating recommendations for coronary angiography following acute myocardial infarction in the elderly: a matched analysis using propensity scores. J Clin Epidemiol 2001;54:387-98.

13. Sipahi I, Akay MH, Dagdelen S, Blitz A, Alhan C. Coronary artery bypass grafting vs percutaneous coronary intervention and long-term mortality and morbidity in multivessel disease: meta-analysis of randomized clinical trials of the arterial grafting and stenting era. JAMA Intern Med 2014;174:223-30. 
14. Weintraub WS, Grau-Sepulveda MV, Weiss JM, et al. Comparative effectiveness of revascularization strategies. N Engl J Med 2012;366:1467-76.

15. Chen MS, John JM, Chew DP, Lee DS, Ellis SG, Bhatt DL. Bare metal stent restenosis is not a benign clinical entity. Am Heart J 2006;151:1260-4.

16. Bainey KR, Norris CM, Graham MM, Ghali WA, Knudtson ML, Welsh RC. Clinical in-stent restenosis with bare metal stents: is it truly a benign phenomenon? Int J Cardiol 2008;128:378-82.

17. Sabate M, Cequier A, Iñiguez A, et al. Everolimus-eluting stent versus bare-met- al stent in ST-segment elevation myocardial infarction (EXAMINATION): 1 year results of a randomised controlled trial. Lancet 2012;380:1482-90.

18. Valgimigli $M$, Tebaldi $M$, Borghesi $M$, et al. Two-year outcomes after first- or second-generation drug-eluting or baremetal stent implantation in all-comer patients undergoing percutaneous coronary intervention: a pre-specified analysis from the PRODIGY study (PROlonging Dual Antiplatelet Treatment After Grading stent-induced Intimal hyperplasia studY). JACC Cardiovasc Interv 2014;7:20-8.

19. Hannan EL, Wu C, Walford G, et al.
Incomplete revascularization in the era of drug-eluting stents: impact on adverse outcomes. JACC Cardiovasc Interv 2009;2: $17-25$.

20. Généreux P, Palmerini T, Caixeta A, et al. Quantification and impact of untreated coronary artery disease after percutaneous coronary intervention: the residual SYNTAX (Synergy Between PCI with Taxus and Cardiac Surgery) score. J Am Coll Cardiol 2012;59:2165-74.

Copyright (c) 2015 Massachusetts Medical Society.

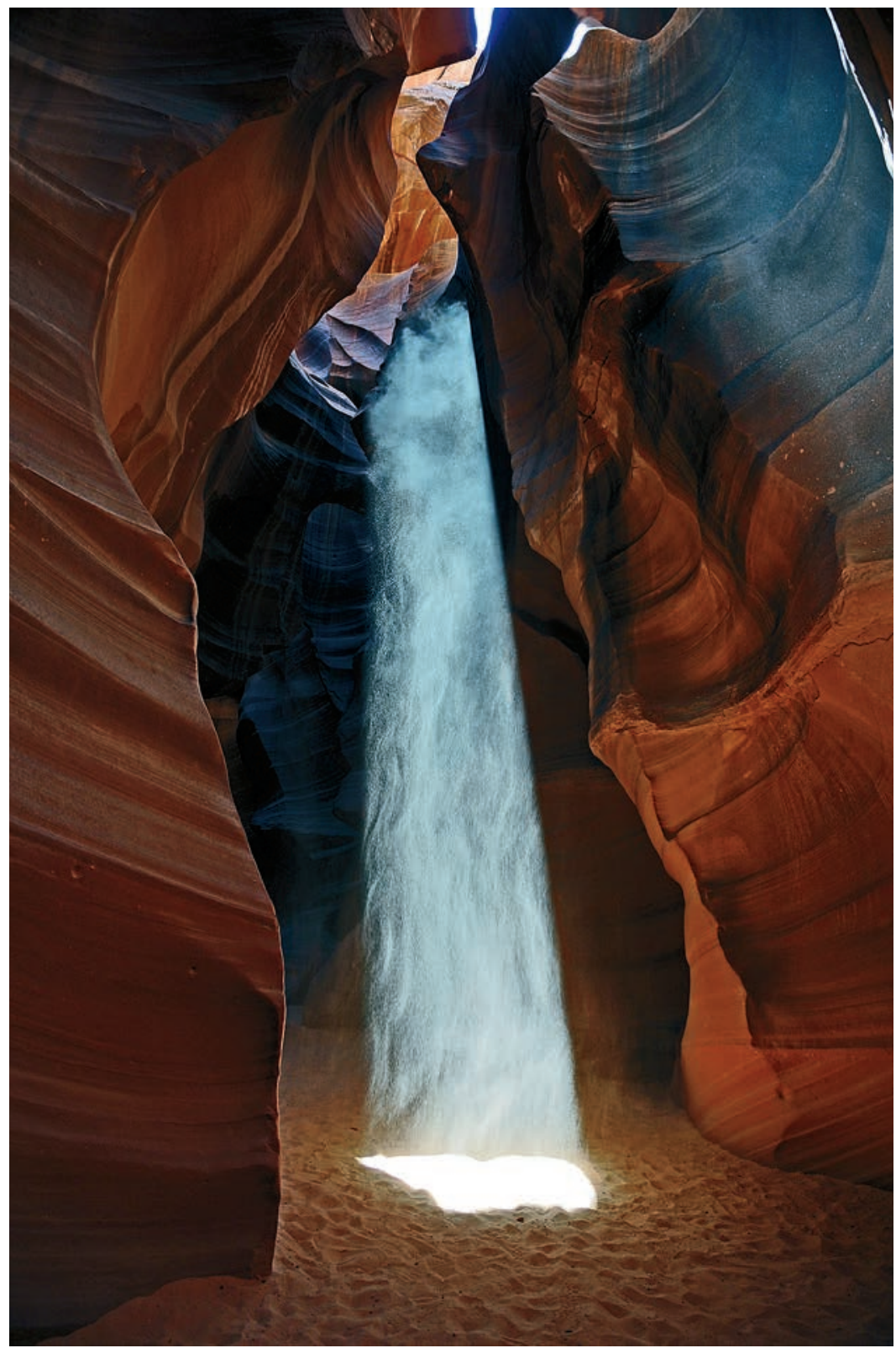

